Purdue University

Purdue e-Pubs

CTRC Research Publications

Cooling Technologies Research Center

2011

\title{
Evaporative Heat and Mass Transfer from the Free Surface of a Liquid Wicked into a Bed of Spheres
}

Christopher P. Migliaccio

Purdue University

S V. Garimella

Purdue University, sureshg@purdue.edu

Follow this and additional works at: http://docs.lib.purdue.edu/coolingpubs

Migliaccio, Christopher P. and Garimella, S V., "Evaporative Heat and Mass Transfer from the Free Surface of a Liquid Wicked into a Bed of Spheres" (2011). CTRC Research Publications. Paper 153.

http://dx.doi.org/10.1016/j.ijheatmasstransfer.2011.03.042

This document has been made available through Purdue e-Pubs, a service of the Purdue University Libraries. Please contact epubs@purdue.edu for additional information. 


\title{
Evaporative Heat and Mass Transfer from the Free Surface of a Liquid Wicked into a Bed of Spheres
}

\author{
Christopher P. Migliaccio and Suresh V. Garimella ${ }^{\mathbb{I}}$ \\ Cooling Technologies Research Center, an NSF IUCRC \\ School of Mechanical Engineering and Birck Nanotechnology Center \\ Purdue University \\ West Lafayette, IN 47907-2088 USA
}

\begin{abstract}
Evaporation of ethanol from square packed arrays of $3.95 \mathrm{~mm}$ diameter copper spheres in a transparent, enclosed chamber is investigated. The enclosure ensures that relatively saturated vapor conditions exist near the free surface. The desired heat flux is imposed on the copper substrate upon which the copper spheres are mounted, and the liquid level in the bed is maintained by wicking from a continuous supply of liquid provided by a syringe pump. Transparent windows in the enclosure allow for visualization of the evaporating liquid meniscus shape, which is recorded for different liquid feeding rates and heat fluxes. Experimentally measured meniscus profiles are compared to analytical results based on surface-energy minimization. A meniscus microregion is defined from the contact line to the length where the liquid thickness reaches $10 \mu \mathrm{m}$. An approximate kinetic theory-based analysis estimates that up to $\sim 55 \%$ of the total meniscus mass transfer occurs in this microregion.
\end{abstract}

Keywords: Phase change, evaporation, thin film, liquid-vapor interface, heat pipe, sintered material

\footnotetext{
II Author to whom correspondence should be addressed: 765-494-5621, sureshg@purdue.edu
} 


\section{Nomenclature}

$\begin{array}{llll}h_{f g} & \text { latent heat of vaporization }(\mathrm{kJ} / \mathrm{kg}) & \text { Greek } & \\ k & \text { thermal conductivity }(\mathrm{W} / \mathrm{m} \mathrm{K}) & \psi & \text { mass flow rate }(\mathrm{kg} / \mathrm{s}) \\ m_{\text {net }}^{\prime \prime} & \text { net mass flux }\left(\mathrm{kg} / \mathrm{m}^{2} \mathrm{~s}\right) & \delta & \text { liquid thickness }(\mu \mathrm{m}) \\ M & \text { molecular weight }(\mathrm{kg} / \mathrm{kmol}) & \sigma & \text { accommodation coefficient } \\ p & \text { pressure }\left(\mathrm{N} / \mathrm{m}^{2}\right) & & \\ R & \text { universal gas constant }(\mathrm{J} / \mathrm{mol} \mathrm{K}) & \text { Subscripts } \\ T & \text { temperature }\left({ }^{\circ} \mathrm{C}\right) & e q u & \text { equilibrium } \\ q_{n e t}^{\prime \prime} & \text { net heat flux }\left(\mathrm{W} / \mathrm{m}^{2}\right) & l & \text { liquid } \\ & & l v & \text { liquid-vapor interface } \\ & & s a t & \text { saturated }\end{array}$




\section{Introduction}

Over the past few decades, heat pipes have become essential components in thermal systems encountered in a variety of applications including electronics cooling, spacecraft, and cryogenic processes. Heat pipes initially received attention because they exhibited characteristic effective thermal conductivities that were orders of magnitude higher than that of similarly sized rods of solid metal [1]. Based on the passive vaporization-condensation cycle of a working fluid in a sealed chamber, heat pipes efficiently transfer heat from the evaporator to the condenser across minimal temperature gradients.

The porous wick medium of a heat pipe provides the means for passive transport of the liquid from the condenser to the evaporator section by capillary forces. The permeability of the wick governs the ease with which liquid can flow from the condenser to the evaporator. When the capillary pressure is unable to overcome the retarding forces (e.g., viscous and in some cases gravitational), the liquid flow to the evaporator section diminishes, resulting in dry-out of the wick. A number of researchers have experimentally investigated the parameters that affect the dry-out limit (i.e., critical heat flux) of wicks. Iverson et al. [2] tested vertically oriented, sintered copper wicks of varying pore size under partially saturated conditions. Careful liquid measurements were used to determine the amount of evaporative mass transfer from the wick, and good agreement was found between expected and measured values. The effects of wick thickness, volumetric porosity, and mesh size on critical heat flux (CHF) of sintered wire mesh wicks were investigated by $\mathrm{Li}$ et al. [3] and $\mathrm{Li}$ and Peterson [4]. The minimum meniscus radius in the wick structure was found to control the CHF. A thin-film evaporation heat transfer regime was delineated, and was found to provide the highest heat transfer capability, just before the occurrence of dry-out. Williams and Harris [5] devised a test setup capable of measuring the heat transfer limit, conductance, and effective thermal conductivity of planar wicks at any orientation relative to gravity. Most recently, the effects of wick thickness and particle size on the thermal resistance of sintered powder wicks was investigated by Weibel et al. [6]. For a given wick thickness, an optimum particle size was identified which maximized the heat transfer coefficient.

Hanlon and Ma [7] conducted experiments and presented a two-dimensional model to predict the overall heat transfer capability of a sintered wick structure. Their results highlighted 
the importance of thin-film evaporation at the top surface of a wick. They concluded that careful optimization of particle size, porosity, and wick thickness can maximize the evaporative heat transfer from a sintered wick. Building from conclusions drawn from Ref. [7], Ma et al. [8] designed and tested a heat pipe heat sink that exploited the excellent heat transfer characteristics associated with thin-film evaporation and was capable of dissipating $800 \mathrm{~kW} / \mathrm{m}^{2}$. Jiang et al. [9] used infrared thermography to study the evaporation of ethanol wetting glass cylinders, finding that $20-40 \%$ of the total heat was dissipated from an evaporating film region on the order of 100 $\mu \mathrm{m}$ in length. More recent investigations utilizing infrared thermography have shown that 50 $\mu \mathrm{m}$-long microregions can account for up to $45 \%$ and $70 \%$ of total meniscus heat transfer in Vgrooves [10] and channels [11], respectively.

Modeling efforts have also addressed the heat and mass transfer from the microregion of an extended meniscus. Evaporation from triangular grooves was investigated in $[12,13]$. The amount of heat transfer attributed to microregions of menisci varied from $8 \%$ to $45 \%$ of the total based on the definitions used by different authors. A detailed numerical model of evaporation from a meniscus confined in a microchannel [14] was developed by Wang et al. They showed that a meniscus microregion of thickness $<1 \mu \mathrm{m}$ can account for over $50 \%$ of the total meniscus heat transfer. Demsky and Ma [15] developed a mathematical model predicting evaporation and fluid flow in a meniscus formed on a curved surface. They noted that the additional curvature in the thin-film region of the meniscus formed on a curved surface produces a larger maximum heat flux when compared to that from a thin-film region on a flat surface.

The phase change process in wicks of different size scales has been visualized in an effort to better understand the heat and mass transfer occurring at the pore level. Wong and Kao [16] visualized the boiling process in the evaporator section of a transparent heat pipe with a mesh wick. Effects of fluid charge, heat load, and wick structure on evaporator temperature were examined. Weibel et al. [6] performed in situ visualization of evaporation and boiling in sintered powder wicks with particle diameters up to $355 \mu \mathrm{m}$ which allowed for the heat transfer performance to be precisely correlated to the observed heat transfer regimes. Boiling in a bed of staggered glass beads (diameters 3.5 and $7 \mathrm{~mm}$ ) was visualized at different heat fluxes and with different fluids by Peng and co-workers $[17,18]$. They found that nucleation and bubble growth was strongly influenced by pore size, and that smaller pore sizes exhibited higher heat transfer coefficients due to stronger liquid replenishment processes. Liao and Zhao [19] observed boiling 
in a two-dimensional wick structure of staggered $2 \mathrm{~mm}$ diameter silver-copper cylinders at heat flux levels up to and exceeding critical heat flux. Li et al. [20] visually confirmed earlier hypotheses regarding evaporative heat transfer in wire wicks. In studying microscale sintered copper mesh screen wicks, they found that nucleate boiling and thin-film evaporation modes were both important at low and moderate heat fluxes, but at high heat fluxes, thin-film evaporation was the dominant mode until dry-out occurred. More recently, Ranjan et al. [21] computed the thin liquid films formed in common wick structures (e.g., ribs, cylinders, spheres) in an effort to identify the microstructure that provides the maximum wicking action while optimizing thin-film heat transfer. On the basis of the generated capillary pressure, thin-film and total liquid surface areas, and conduction resistance of liquid, hexagonally packed spheres were found to provide the best performance among the microstructures considered in the study.

The present work aims to complement past studies by providing well-characterized heat and mass transfer measurements with a macroscale wick structure that can be used for validation of a pore-level numerical model. While past investigations of evaporative heat transfer in macroscale geometries were typically performed under open-to-air conditions [9-11], the macrowick in this work is exposed to surroundings saturated with the vapor of the working fluid. A square-packed array of nine $3.95 \mathrm{~mm}$ diameter copper spheres is attached to a heated copper base that is enclosed by a chamber with transparent viewing windows. Thermocouples installed at different locations throughout the facility record temperatures that would be needed as inputs in modeling efforts. The liquid lost to evaporation is replaced by a syringe pump that continuously feeds room temperature liquid at the base of the macrowick. A goniometer is used to image the liquid meniscus as it wets the spheres. A kinetic theory-based interfacial transport analysis is used to estimate the mass transfer attributable to a microregion of up to $10 \mu \mathrm{m}$ thickness.

\section{Experimental Setup and Procedures}

The test setup is shown schematically in Fig. 1 with the main components labeled. The test piece is a copper heater block with an array of spheres attached to the top surface (measuring 16 $\mathrm{mm} \times 16 \mathrm{~mm}$ ) and a film heater attached to the bottom surface. The copper spheres (4 mm initial diameter, Salem Ball Co.) are bonded with thermally conducting epoxy (Duralco 132, Cotronics Corp.) to the top surface of the heater block. Heat is supplied to the block by a film heater 
(HK5578R9.9L12A, Minco) attached to the bottom of the heater block. The space below the film heater is well insulated with shaped sections of foam insulation. Before the spheres are attached to the heater block, the components undergo a standard acetone/methanol degreasing followed by a weak piranha etch (40:3:1, $\left.\mathrm{H}_{2} \mathrm{O}: \mathrm{H}_{2} \mathrm{SO}_{4}: \mathrm{H}_{2} \mathrm{O}_{2}\right)$ to strip the oxide layer. $25 \mu \mathrm{m}$ of material was etched away during cleaning, leaving the diameter of the spheres at $3.95 \mathrm{~mm}$. Obtaining consistent attachment of the spheres to the copper block surface proved to be challenging. Since it was desired to maintain the spherical geometry of the balls, sintering was not a viable option. Attachment by sheet solder was tested; however, non-uniform attachment beads were observed. The method ultimately chosen was to deposit thermally conducting epoxy on the heater block surface using a syringe. In this manner, the amount of epoxy used for attachment was precisely controlled. Relatively large epoxy beads $(\sim 3.1 \mathrm{~mm}$ diameter for the $3.95 \mathrm{~mm}$ pitch; $\sim 3.3 \mathrm{~mm}$ diameter for the $5 \mathrm{~mm}$ pitch) were used to maintain the strength of the attachment. A removable grid frame and weights were used to hold the spheres in place while the epoxy cured. The epoxy beads provided a low-resistance bond, with the temperature difference between the copper heater block and attached sphere measured to be $\sim 3.5-4{ }^{\circ} \mathrm{C}$ during the experiments. The copper heater blocks with the sphere arrays used in the experiments are shown in Fig. 2.

The test piece fits tightly into a polyetheretherketone (PEEK) holder block; this material is an insulating thermoplastic with good high-temperature structural integrity. The block contains a slender interior groove through which thermocouples from the block and sphere are routed. The outer edges of the top surface of the holder block contain large grooves which collect the ethanol condensate. A retaining wall made of polycarbonate surrounds the wick structure and contains the fluid (see Fig. 1b). Ethanol was chosen as the working fluid due to its highly wetting behavior on copper [22]. All joints are sealed with solvent-resistant sealant (130, Dow Corning). Due to the low surface tension of ethanol, thick beads of sealant were required to seal system (visible in Fig. $1 \mathrm{~b}$ between liquid retaining wall and copper heater block).

In an effort to more closely replicate conditions in a working two-phase device, an enclosure was fabricated to contain the vapor. The enclosure is made of a $50.8 \mathrm{~mm}(2 \mathrm{in})$ square crosssection polycarbonate tube, with an acrylic top wall and the PEEK holder block forming the bottom wall. The three components snap together, and grooves machined in the holder block and acrylic top accommodate O-rings that seal the enclosure walls between them. Clamps are 
used to compress the O-rings to maintain a tight seal. The system is not air-tight; however, by enclosing the system, the vapor concentration gradient, especially near the evaporating surface, is much weaker than it would be in an open-to-air system. As a result, the vapor temperature along the evaporating interface is assumed to be uniform. A small piece of absorbent fabric and a plug are inserted into the drainage hole of the enclosure to continuously remove condensate collected in the holder block groove. The system is initially run in excess of 120 min to ensure that all water vapor in the enclosure has been removed. Windows for viewing the evaporating meniscus are inserted and sealed into stepped holes machined into the sides of the enclosure. The interior surface of the glass windows is covered with a layer of anti-fog film (Film Specialties, Inc.) which prevents the formation of condensation droplets on the window surface, which would otherwise obscure the view.

While the copper heater block contains four clearance holes for $0.508 \mathrm{~mm}$ (0.02 in) sheathed thermocouples (TMTSS-020U-6, Omega Engineering, Inc.), spaced $2 \mathrm{~mm}$ apart in the direction perpendicular to the film heater to monitor the temperature gradient in the block, the modest heat fluxes in the current experiments prevent the measurement of temperature gradients in the heater block with any reasonable accuracy. For the present work, the copper heater block can be treated as isothermal since all four thermocouples inserted into the heater block read the same temperature within $\pm 0.025{ }^{\circ} \mathrm{C}$. Bulk vapor temperature in the chamber is measured by a thermocouple that is routed through the enclosure walls. A $0.508 \mathrm{~mm}(0.02 \mathrm{in})$ diameter hole is drilled to the center of one of the copper spheres, into which a 40 gauge $(0.08 \mathrm{~mm})$, type-T thermocouple (Omega Engineering, Inc.) is epoxied. All thermocouples are referenced to a highstability ice point cell (Omega Engineering, Inc.), and temperatures are recorded at $5 \mathrm{~s}$ intervals with a data acquisition system (34970A, Agilent Technologies, Inc.). The uncertainty in temperature measurements so obtained is estimated to be $\pm 0.3^{\circ} \mathrm{C}$.

Liquid lost to evaporation is replaced by a syringe pump (PHD2000, Harvard Apparatus) which continuously feeds room-temperature $\left(21.5^{\circ} \mathrm{C}\right)$ liquid to the test piece by way of a $149 \mu \mathrm{m}$ inner-diameter glass capillary tube. The uncertainty in mass flow rate is $0.35 \%$. The feeder tube is routed through the polycarbonate liquid-retaining wall and supplies fluid at the base of the macrowick, into the pool of liquid that develops at the base of the spheres. As the liquid wets the spheres, images of the meniscus that forms are captured by a goniometer (CAM 100, KSV Instruments, Ltd.) with a resolution of $1.78 \mu \mathrm{m} /$ pixel. The retaining wall heights for the 3.95 
$\mathrm{mm}$ and $5 \mathrm{~mm}$ pitch experiments are $1.75 \mathrm{~mm}$ and $2.75 \mathrm{~mm}$, respectively. Due to the lower capillary pressure provided by the $5 \mathrm{~mm}$ pitch system, a higher retaining wall is required to bring the liquid up to a level that can be imaged with the goniometer.

Three parameters are varied in the experiments: input heat flux, liquid feeding flow rate, and sphere pitch. For each data point, the input heat flux and feeding flow rate are set to the specified values, and the system is allowed to reach a steady state, which takes about one hour. The uncertainty in power supplied to the film heater by the power supply (Sorensen DLM 807.5 ) is less than $1 \%$. The system is considered to have achieved a steady state when the liquid meniscus, which is continuously monitored using the video capability of the goniometer, has remained static for $20 \mathrm{~min}$. Once steady state has been reached, meniscus images are recorded via the goniometer. The average temperature of the heater block during the steady period is used to estimate the net heat flux to which the macrowick is subjected. The temperature of the heater block can fluctuate by up to $\pm 0.05^{\circ} \mathrm{C}$ during the steady period, which corresponds to a change of less than $0.3 \%$ in the net heat flux. A simple, conduction-based model of the heater block, holder block, and insulation is formulated in ANSYS [23] to estimate heat losses to ambient. Thermal interface resistances are neglected and a combined radiation and natural convection coefficient of $14 \mathrm{~W} / \mathrm{m}^{2} \mathrm{~K}$ is assumed at the exterior faces. Based on this model, losses in the system are estimated to be $\sim 40 \%$ of the applied heat flux. Tables 1 and 2 summarize the test cases studied in this experiment.

Images captured by the goniometer are digitally processed using an edge-detection algorithm in MATLAB [24]. The meniscus interface data are then fit with a fourth-order polynomial. The uncertainty in the meniscus shape curve fit is up to $\pm 3.0 \mu \mathrm{m}$, depending on the case. Fig. 3 shows representative raw and processed images. Based on this curve fit to the meniscus shape, a separate MATLAB program is used to calculate the minimum distance from discrete points on the meniscus to the sphere, yielding an expression for film thickness as a function of distance along the interface as measured from the contact line. 


\section{Results and Discussion}

\subsection{Meniscus Shape Determination}

The meniscus shape of an evaporating liquid film is determined by the capillary and disjoining pressure gradients; the meniscus shape in turn governs the amount of liquid fed to the contact-line region. At steady-state operation, the liquid feeding rate supplied to the macrowick is equal to the total evaporation rate. Fig. 4 illustrates that at a constant heat flux, an increase in feeding rate leads to an increase in interfacial area. As the liquid level rises, the contact line of the meniscus moves higher up along the sphere surface.

At a constant feeding rate, an increase in heat flux causes the meniscus to recede to the point where the capillary pressure in the system is able to supply the necessary liquid to the contactline region for evaporation. The result is a decrease in interfacial area, as shown in Fig. 5. An additional 20\% step in the heat flux used in case 6 was found to lead to dry-out of the wick.

Because the goniometer images are only representative of one cross-sectional plane through the meniscus, the program SURFACE EVOLVER (SE) [25] is used to determine the free-surface shape of the entire meniscus under the given conditions. Fig. 6 shows the experimentally obtained meniscus profile with that obtained from the SE model at the same plane superimposed. The good agreement seen in the figure is obtained in all the cases. The user-defined contact angle input to the model is $10^{\circ}$, which is within the range given by Faghri [22] for the ethanol/copper combination. As illustrated in Fig. 7, by modeling the unit cell of the macrowick, the influence on the meniscus shapes of the interactions between adjacent spheres are captured. The presence of adjacent spheres leads to a non-axisymmetric meniscus shape. This effect is more pronounced at the $3.95 \mathrm{~mm}$ pitch because the spheres are touching.

\subsection{Microregion Mass Transfer}

In the present work, a microregion is defined as being the region extending from the contact line to the point where the liquid film is $10 \mu \mathrm{m}$ thick. The shape of the microregion profile, which varies with azimuthal location around the sphere, is needed to estimate the mass transfer attributable to the microregion. While the goniometric imaging only captures the profile in one plane, the SE model calculates the free-surface shape of the entire meniscus and returns the 
surface area of the meniscus that lies within a normal distance of $10 \mu \mathrm{m}$ from the sphere surface. If the planar profile obtained by goniometric imaging is assumed to be valid around the entire sphere perimeter, the microregion surface area obtained is on average $\sim 25 \%$ higher than the microregion surface area calculated by SE, thus leading to an over-prediction of microregion mass transfer. As a result, an effective microregion profile is defined based on the surface area calculated by SE.

The microregion film thickness varies linearly with position along the interface, and the slope of the profile changes based on the azimuthal position of the contact line on the sphere. The maximum profile slope for a given case occurs in the viewing plane (see Fig. 3), and the minimum slope occurs at an azimuthal location shifted $\pi / 4$ radians on either side of the viewing plane (maximum slope difference $\sim 15 \%$ ). An effective microregion profile is calculated that has an intermediate slope such that the surface area of the microregion matches that calculated by the SE model. Assuming the effective profile is valid around the entire wetted perimeter of the sphere, an expression for mass flux based on conduction heat transfer through the liquid film is given by

$$
m_{n e t}^{\prime \prime}=\frac{k_{l}\left(T_{w}-T_{l v}\right)}{\delta h_{f g}}
$$

where $\delta$ is the liquid thickness along the liquid-vapor interface, the wall temperature $T_{\mathrm{w}}$ is the sphere temperature, and $T_{l v}$ is the interface temperature.

An equivalent expression for mass flux is based on the kinetic theory-based interfacial transport expression proposed by Schrage [26]

$$
m_{n e t}^{\prime \prime}=\frac{2 \sigma}{2 \sigma-1}\left(\frac{M}{2 \pi R}\right)^{1 / 2}\left(\frac{p_{v_{-} e q u}\left(T_{l v}\right)}{T_{l v}{ }^{1 / 2}}-\frac{p_{v}}{T_{v}^{1 / 2}}\right) .
$$

In the present work, the accommodation coefficient, $\sigma$ is taken as unity, and the equilibrium vapor pressure is taken as the saturation pressure corresponding to the interface temperature, $p_{\mathrm{v} \_ \text {equ }}\left(T_{\mathrm{lv}}\right)=p_{\text {sat }}\left(T_{\mathrm{lv}}\right)$ [27]. As mentioned in Section 2, the enclosure leads to approximately saturated conditions in the domain and serves to dampen the concentration gradients. The vapor temperature at the interface is thus assumed to be uniform. 
Using ethanol properties at $60^{\circ} \mathrm{C}\left(k_{1}=0.171 \mathrm{~W} / \mathrm{m} \mathrm{K}, h_{\mathrm{fg}}=988.9 \mathrm{~kJ} / \mathrm{kg}, M=46.07 \mathrm{~kg} / \mathrm{kmol}\right.$, $R=8.3145 \mathrm{~J} / \mathrm{mol} \mathrm{K}$ ), all variables on the right hand side of Eqs. (1) and (2) are known with the exception of the vapor temperature at the interface, $T_{\mathrm{lv}}$, and in the adjacent vapor, $T_{v}$, as well as the corresponding vapor pressures, $p_{v_{-} e q u}\left(T_{l_{v}}\right)$ and $p_{\mathrm{v}}$, respectively. The intensity of mass transfer far from the contact line where the liquid thickness is on the order of 10 's of $\mu \mathrm{m}$ is expected to be insignificant [14]. With knowledge of the total evaporative mass flux of the wick (i.e., the feeding flow rate), assuming the mass flux to be zero at a length along the meniscus interface of $300 \mu \mathrm{m}$, Eqs. (1) and (2) can be equated, and $T_{\mathrm{v}}$ and $T_{l v}$ can be solved for numerically. With all variables known, the mass flux along the interface is found. Figures 8 and 9 show the mass flux and temperature, respectively, along the interfacial coordinate for case 7. The plots are truncated at an interface coordinate of $1.78 \mu \mathrm{m}$ due to the resolution of the goniometer. Uncertainty in the sphere wall temperature leads to a $\sim 15 \%$ uncertainty in mass flux (see Fig. 8). As expected, the mass flux near the contact line rises asymptotically to a large value and trails off to zero far from the contact line. Similarly, the interface temperature providing the driving potential for evaporation in Eq. (2) trends from the highest values near the contact line to the vapor temperature value far from the contact line.

With the evaporative mass flux distribution along the interface known, the mass flux contribution of the microregion relative to that from the total meniscus can be estimated. Past researchers [9-14] have found that microregions of various definitions can account for 8-70\% of the total mass transfer of the meniscus. The present work estimates that up to $~ 55 \%$ of the total meniscus mass transfer occurs in a microregion up to $10 \mu \mathrm{m}$ thick. Table 3 presents a brief summary of past efforts. Estimates from the present work are in general agreement with these past investigations. The study with the closest geometric similarity to the present work is Ref. [11], which had a microregion thickness of $\sim 10 \mu \mathrm{m}$. The lower microregion mass flux found in this work is likely attributable to the shorter microregion length considered.

The preceding analysis hinges on the simplification that the effective meniscus profiles calculated from the SE model are valid around the entire wetted perimeter of the spheres. This assumption ensures that the correct microregion surface area is used, while neglecting the azimuthal variation of microregion profile slope. As the maximum range of microregion slopes in the cases considered is $\sim 15 \%$, using an effective microregion profile is a reasonable approximation. Table 4 reports the calculated surface area, effective length, and mass flux 
fraction of the microregion based on this assumption. Improved accuracy could be attained by using a measured or calculated 3-D meniscus profile in the analysis.

\section{Conclusions}

Evaporation from a meniscus formed by liquid ethanol wicking into an array of $3.95 \mathrm{~mm}$ diameter copper spheres was investigated. The meniscus shape was visualized for different liquid feeding rates and heat fluxes, and a meniscus microregion was defined as extending from the contact line to the point on the meniscus interface where the liquid thickness reached $10 \mu \mathrm{m}$. An effective microregion profile was determined based on the microregion surface area reported from an analytical computation. An approximate kinetic theory-based analysis revealed that up to $\sim 55 \%$ of the total meniscus mass transfer occurs in the microregion, which compares favorably with results from past investigations. The importance of the evaporating microregion to the total meniscus mass transfer is clearly established. Results from these experiments can be used for validating numerical models for pore-level transport analysis in heat pipe wick structures.

\section{Acknowledgement}

The authors acknowledge financial support for this work from the Cooling Technologies Research Center, a National Science Foundation Industry/University Cooperative Research Center at Purdue University. Ram Ranjan of Purdue University assisted in the analytical liquid meniscus computations.

\section{References}

[1] G.M. Grover, T.P. Cotter, C.F. Erickson, Structures of very high thermal conductance, J. Appl. Phys. 35 (6) (1964) 1990-1991.

[2] B.D. Iverson, T.W. Davis, S.V. Garimella, M.T. North, S.S. Kang, J. Thermophys. Heat Transfer 21 (2) (2006) 392-404. 
[3] C. Li, G.P. Peterson, Y. Wang, Evaporation/boiling in thin capillary wicks (I)- wick thickness effects, J. Heat Transf. 128 (12) (2006) 1312-1319.

[4] C. Li, G.P. Peterson, Evaporation/boiling in thin capillary wicks (II)-effects of volumetric porosity and mesh size, J. Heat Transf. 128 (12) (2006) 1320-1328.

[5] R.R. Williams, D.K. Harris, A device and technique to measure the heat transfer limit of a planar heat pipe wick, Exp. Therm. Fluid Sci. 30 (3) (2006) 277-284.

[6] J.A. Weibel, S.V. Garimella, M.T. North, Characterization of evaporation and boiling from sintered powder wicks fed by capillary action, Int. J. Heat Mass Transf. 53 (19-20) (2010) 42044215.

[7] M.A. Hanlon, H.B. Ma, Evaporation heat transfer in sintered porous media, J. Heat Transf. 125 (4) (2003) 644-652.

[8] H.B. Ma, K.P. Lofgreen, G. P. Peterson, An experimental investigation of a high flux heat pipe heat sink, J. Electron. Packag. 128 (1) (2006) 18-22.

[9] J. Jiang, Y.-X. Tao, L. Byrd, Evaporative heat transfer from thin liquid film on a heated cylinder, Int. J. Heat Mass Transf. 43 (1) (2000) 85-99.

[10] C.P. Migliaccio, H.K. Dhavaleswarapu, S.V. Garimella, Temperature measurements near the contact line of an evaporating meniscus V-groove, Int. J. Heat Mass Transf. 54 (7-8) (2011) $1520-1526$.

[11] H.K. Dhavaleswarapu, S.V. Garimella, J.Y. Murthy, Microscale temperature measurements near the triple line of an evaporating thin liquid film, J. Heat Transfer 131 (6) (2009) 061501 (7 pp.).

[12] F.W. Holm, S.P. Goplen, Heat transfer in the meniscus thin film transition region, J. Heat Transf. 101 (3) (1979) 543-547.

[13] P.C. Stephan, C.A. Busse, Analysis of the heat transfer coefficient of grooved heat pipe evaporator walls, Int. J. Heat Mass Transf. 35 (2) (1992) 383-391.

[14] H. Wang, S.V. Garimella, J.Y. Murthy, Characteristics of an evaporating thin film in a microchannel, Int. J. Heat Mass Transf. 50 (19-20) (2007) 3933-3942.

[15] S.M. Demsky, H.B. Ma, Thin film evaporation on a curved surface, Microscale Thermophys. Eng. 8 (3) (2004) 285-299.

[16] S.-C. Wong, Y.-H. Kao, Visualization and performance measurement of operating meshwicked heat pipes, Int. J. Heat Mass Transf. 51 (17-18) (2008) 4249-4259. 
[17] Z. Wang, X.F. Peng, T. Liu, Visualization of boiling phenomena in a bead-packed structure, Exp. Heat Transf. 15 (3) (2002) 177-189.

[18] Z. Wang, X.F. Peng, J.M. Ochterbeck, Dynamic bubble behavior during boiling in beadpacked structures, Int. J. Heat Mass Transf. 47 (22) (2004) 4771-4783.

[19] Q. Liao, T.S. Zhao, A visual study of phase-change heat transfer in a two-dimensional porous structure with a partial heating boundary, Int. J. Heat Mass Transf. 43 (7) (2000) 10891102 .

[20] C. Li, G.P. Peterson, J. Li, N. Koratkar, The visualization of thin film evaporation on thin micro sintered copper mesh screen, in: Proc. ASME Summer Heat Transf. Conf., HT 2008, pp. 645-650.

[21] R. Ranjan, J.Y. Murthy, S.V. Garimella, Analysis of the wicking and thin-film evaporation characteristics of microstructures, J. Heat Transf. 131 (10) (2009) 101001 (10 pp.).

[22] A. Faghri, Heat Pipe Science and Technology, $1^{\text {st }}$ ed., Taylor \& Francis, Washington, DC, 1995.

[23] ANSYS, Academic Research, release 11.0, ANSYS, Inc., Canonsburg, PA, 2007.

[24] MATLAB, The Language of Technical Computing, version 7.6, The Mathworks Inc., Natick, MA, 2008.

[25] K.A. Brakke, The surface evolver, Exp. Math. 1 (1992) 141-165.

[26] R.W. Schrage, A Theoretical Study of Interface Mass Transfer, Columbia University Press, New York, 1953.

[27] H. Wang, J.Y. Murthy, S.V. Garimella, Transport from a volatile meniscus inside an open microtube, Int. J. Heat Mass Transf. 51 (11-12) (2008) 3007-3017. 


\section{LIST OF TABLES}

Table 1. Summary of measurements for cases 1-6 (3.95 mm pitch).

Table 2. Summary of measurements for cases 7-12 (5 mm pitch).

Table 3. Meniscus microregion contribution to total heat/mass transfer from meniscus.

Table 4. Microregion geometry and performance summary.

\section{LIST OF FIGURES}

Fig. 1 a) Schematic illustration of test setup, and b) close-up of test section (shown without the enclosure).

Fig. 2 Copper test pieces with different sphere pitches: $5 \mathrm{~mm}$ (left), $3.95 \mathrm{~mm}$ (right). The holes in the heater block and sphere are thermocouple ports.

Fig. 3 a) Schematic illustration of goniometer viewing plane, and b) raw image from goniometer (top) and after edge detection (bottom) for case 1.

Fig. 4 Meniscus profile dependence on liquid feeding rate $(\psi)$ for: a) cases 1-4 ( $q_{n e t}^{\prime \prime}=3430$ $\left.\mathrm{W} / \mathrm{m}^{2}\right)$, and b) cases 7-10 $\left(q_{n e t}^{\prime \prime}=3420 \mathrm{~W} / \mathrm{m}^{2}\right)$. The dark line represents the sphere surface. The uncertainty in the experimental meniscus shape is up to $\pm 3.0 \mu \mathrm{m}$ at any point.

Fig. 5 Meniscus profile dependence on net heat flux $\left(q_{n e t}^{\prime \prime}\right)$ for: a) cases 4-6 $\left(\psi=8.667 \times 10^{-7}\right.$ $\mathrm{kg} / \mathrm{s})$, and b) cases 10-12 $\left(\psi=8.667 \times 10^{-7} \mathrm{~kg} / \mathrm{s}\right)$. The uncertainty in the experimental meniscus shape is up to $\pm 3.0 \mu \mathrm{m}$ at any point.

Fig. 6 Experimental meniscus profile (only selected points included for clarity) superimposed on calculated profile for case 7. The uncertainty in the experimental meniscus shape is $\pm 1.8 \mu \mathrm{m}$ at any point. The calculated points represent vertices that are within $\pm 5 \mu \mathrm{m}$ of the experimentally imaged cross-sectional plane.

Fig. 7 Calculated meniscus shapes for cases 6 and 12. While the menisci in all cases are nonaxisymmetric, cases 1-6 are more influenced by the presence of adjacent spheres as the meniscus rises higher in the viewing plane due to capillarity. In all cases, the microregion of $10 \mu \mathrm{m}$ thickness is shortest in the viewing plane and longest at a location shifted azimuthally by $\pi / 4$ radians (maximum difference $\sim 15 \%$ ).

Fig. 8 Interfacial mass flux for case 7. Inset: interfacial mass flux in microregion with error bars. This figure is representative of other cases.

Fig. 9 Interfacial temperature for case 7. This figure is representative of other cases. 
Table 1. Summary of measurements for cases 1-6 (3.95 mm pitch).

\begin{tabular}{|c|c|c|c|c|c|c|}
\hline Case & 1 & 2 & 3 & 4 & 5 & 6 \\
\hline $\begin{array}{l}\text { Mass flow rate, } \\
\mathrm{kg} / \mathrm{s}\end{array}$ & $6.667 \times 10^{-7}$ & $7.333 \times 10^{-7}$ & $8.000 \times 10^{-7}$ & $8.667 \times 10^{-7}$ & $8.667 \times 10^{-7}$ & $8.667 \times 10^{-7}$ \\
\hline $\begin{array}{l}\text { Applied heat flux, } \\
\mathrm{W} / \mathrm{m}^{2}\end{array}$ & 5781 & 5781 & 5781 & 5781 & 6875 & 8063 \\
\hline $\begin{array}{l}\text { Net heat flux, } \\
\mathrm{W} / \mathrm{m}^{2}\end{array}$ & 3430 & 3430 & 3430 & 3430 & 4167 & 4983 \\
\hline $\begin{array}{c}\text { Heater block } \\
\text { temperature, }{ }^{\circ} \mathrm{C}\end{array}$ & 59.5 & 59.5 & 59.0 & 58.8 & 63.9 & 70.6 \\
\hline $\begin{array}{c}\text { Sphere } \\
\text { temperature, }{ }^{\circ} \mathrm{C}\end{array}$ & 56.4 & 56.4 & 55.9 & 55.8 & 60.4 & 66.6 \\
\hline $\begin{array}{c}\text { Bulk vapor } \\
\text { temperature }{ }^{*}{ }^{\circ} \mathrm{C}\end{array}$ & 45.9 & 45.7 & 45.7 & 45.6 & 50.7 & 51.3 \\
\hline
\end{tabular}

* vapor temperature measured above meniscus, $5 \mathrm{~mm}$ from heater block top surface 
Table 2. Summary of measurements for cases 7-12 (5 mm pitch).

\begin{tabular}{|c|c|c|c|c|c|c|}
\hline Case & 7 & 8 & 9 & 10 & 11 & 12 \\
\hline $\begin{array}{l}\text { Mass flow rate, } \\
\mathrm{kg} / \mathrm{s}\end{array}$ & $6.667 \times 10^{-7}$ & $7.333 \times 10^{-7}$ & $8.000 \times 10^{-7}$ & $8.667 \times 10^{-7}$ & $8.667 \times 10^{-7}$ & $8.667 \times 10^{-7}$ \\
\hline $\begin{array}{l}\text { Applied heat flux, } \\
\qquad \mathrm{W} / \mathrm{m}^{2}\end{array}$ & 5766 & 5766 & 5766 & 5766 & 6531 & 7688 \\
\hline $\begin{array}{l}\text { Net heat flux, } \\
\mathrm{W} / \mathrm{m}^{2}\end{array}$ & 3420 & 3420 & 3420 & 3420 & 3958 & 4752 \\
\hline $\begin{array}{c}\text { Heater block } \\
\text { temperature, }{ }^{\circ} \mathrm{C}\end{array}$ & 59.9 & 59.5 & 59.7 & 59.4 & 64.1 & 70.7 \\
\hline $\begin{array}{c}\text { Sphere } \\
\text { temperature, }{ }^{\circ} \mathrm{C}\end{array}$ & 56.8 & 56.6 & 56.4 & 56.3 & 60.6 & 66.7 \\
\hline $\begin{array}{c}\text { Bulk vapor } \\
\text { temperature }{ }^{\dagger},{ }^{\circ} \mathrm{C}\end{array}$ & 50.4 & 48.8 & 50.2 & 49.1 & 52.7 & 56.6 \\
\hline
\end{tabular}

${ }^{\dagger}$ vapor temperature measured above meniscus, $4 \mathrm{~mm}$ from heater block top surface 
Table 3. Meniscus microregion contribution to total heat/mass transfer from meniscus.

\begin{tabular}{|c|c|c|c|c|}
\hline Ref. & Geometry & $\begin{array}{l}\text { Liquid/solid } \\
\text { combination }\end{array}$ & $\begin{array}{l}\text { Microregion } \\
\text { definition }\end{array}$ & $\begin{array}{l}\text { Microregion } \\
\text { contribution }\end{array}$ \\
\hline Jiang et al. [9] & Cylinders & Ethanol/glass & $\sim 100 \mu \mathrm{m}$ long & $40 \%$ \\
\hline Migliaccio et al. [10] & V-groove & Heptane/quartz & $50 \mu \mathrm{m}$ long & $45 \%$ \\
\hline $\begin{array}{c}\text { Dhavaleswarapu et } \\
\text { al. [11] }\end{array}$ & Channel & Heptane/quartz & $50 \mu \mathrm{m}$ long & $70 \%$ \\
\hline $\begin{array}{c}\text { Holm and Goplen } \\
\text { [12] }\end{array}$ & Groove & $\begin{array}{c}\text { Water/unspecified } \\
\text { metal }\end{array}$ & $12 \mu \mathrm{m}$ thick & $8 \%$ \\
\hline $\begin{array}{c}\text { Stephan and Busse } \\
\text { [13] }\end{array}$ & Groove & Ammonia/aluminum & $1 \mu \mathrm{m}$ long & $45 \%$ \\
\hline Wang et al. [14] & Channel & Octane/silicon & $1 \mu \mathrm{m}$ thick & $50 \%$ \\
\hline
\end{tabular}


Table 4. Microregion geometry and performance summary.

\begin{tabular}{|c|c|c|c|}
\hline Case & $\begin{array}{c}\text { Calculated surface } \\
\text { area, } \mathrm{mm}^{2}\end{array}$ & Effective length, $\mu \mathrm{m}$ & $\begin{array}{c}\text { Mass flux } \\
\text { contribution, \% }\end{array}$ \\
\hline 1 & 2.57 & 27.9 & 53 \\
\hline 2 & 2.61 & 28.8 & 54 \\
\hline 3 & 2.70 & 30.3 & 55 \\
\hline 4 & 2.62 & 30.0 & 55 \\
\hline 5 & 2.76 & 30.3 & 55 \\
\hline 6 & 3.22 & 33.5 & 57 \\
\hline 7 & 3.23 & 30.9 & 55 \\
\hline 8 & 3.13 & 30.3 & 55 \\
\hline 9 & 3.12 & 30.7 & 55 \\
\hline 10 & 2.88 & 29.2 & 54 \\
\hline 11 & 3.24 & 31.4 & 56 \\
\hline 12 & 4.33 & 39.8 & 60 \\
\hline
\end{tabular}




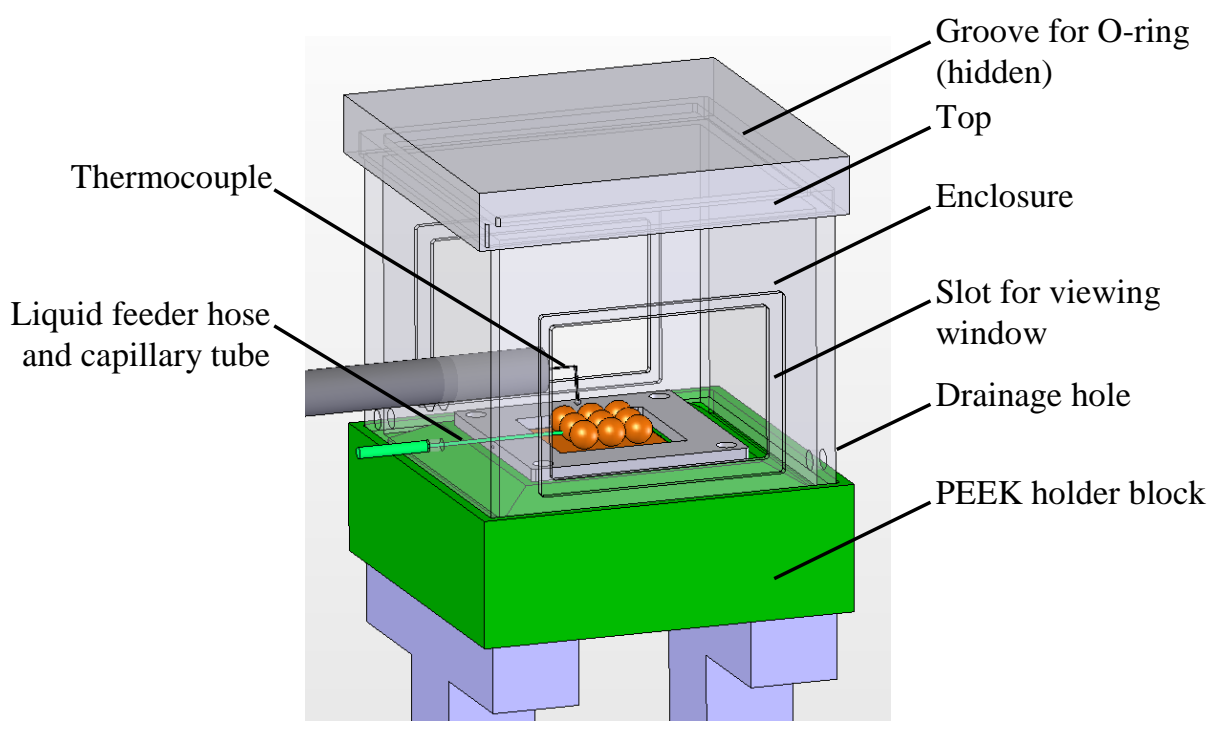

a)

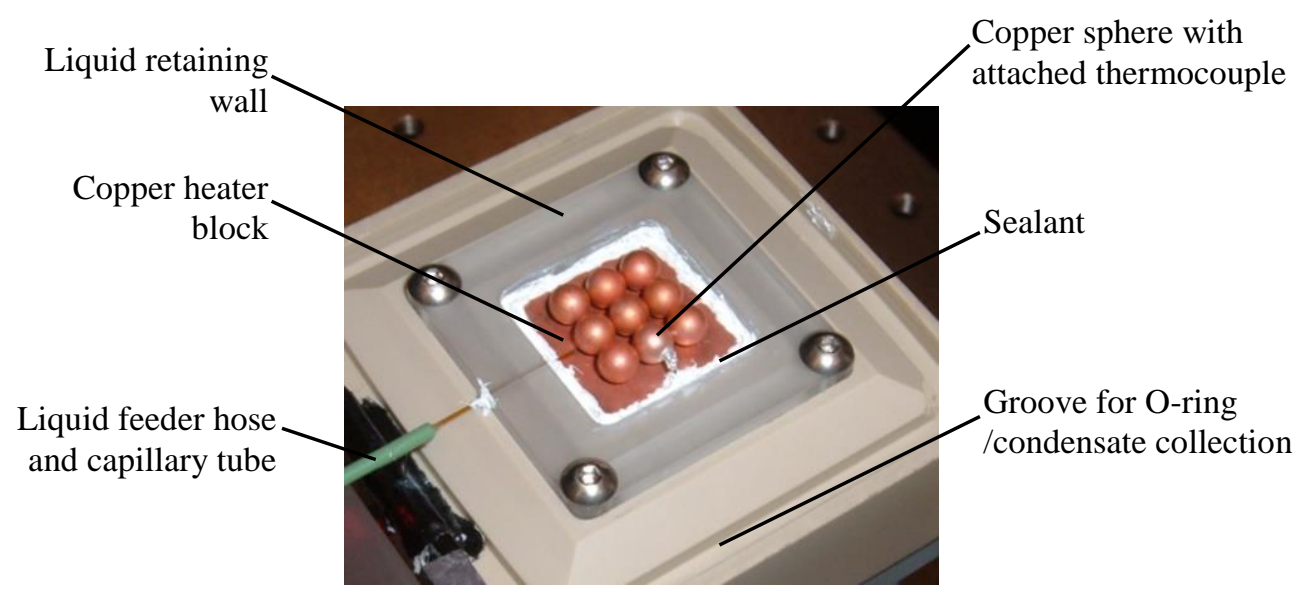

b)

Fig. 1 a) Schematic illustration of test setup, and b) close-up of test section (shown without the enclosure). 


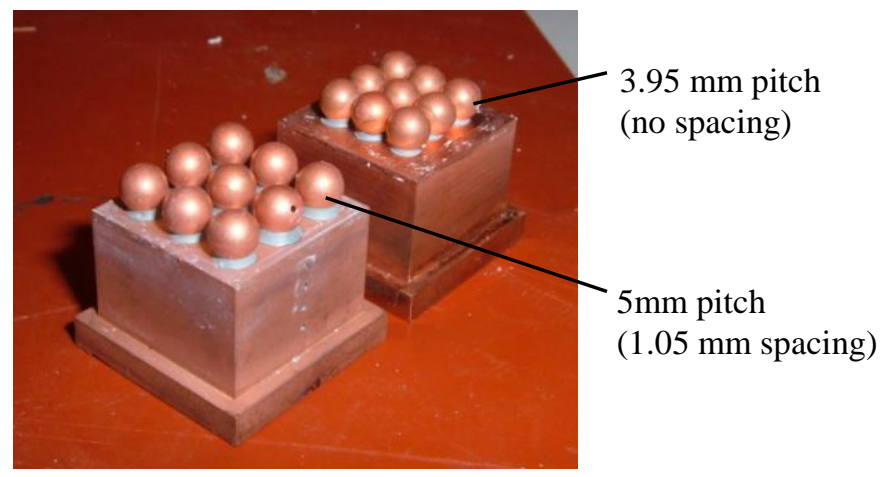

Fig. 2 Copper test pieces with different sphere pitches: $5 \mathrm{~mm}$ (left), $3.95 \mathrm{~mm}$ (right). The holes in the heater block and sphere are thermocouple ports. 


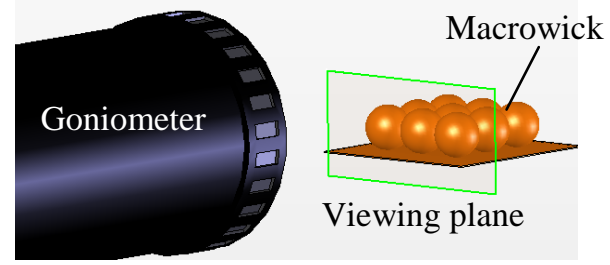

a)
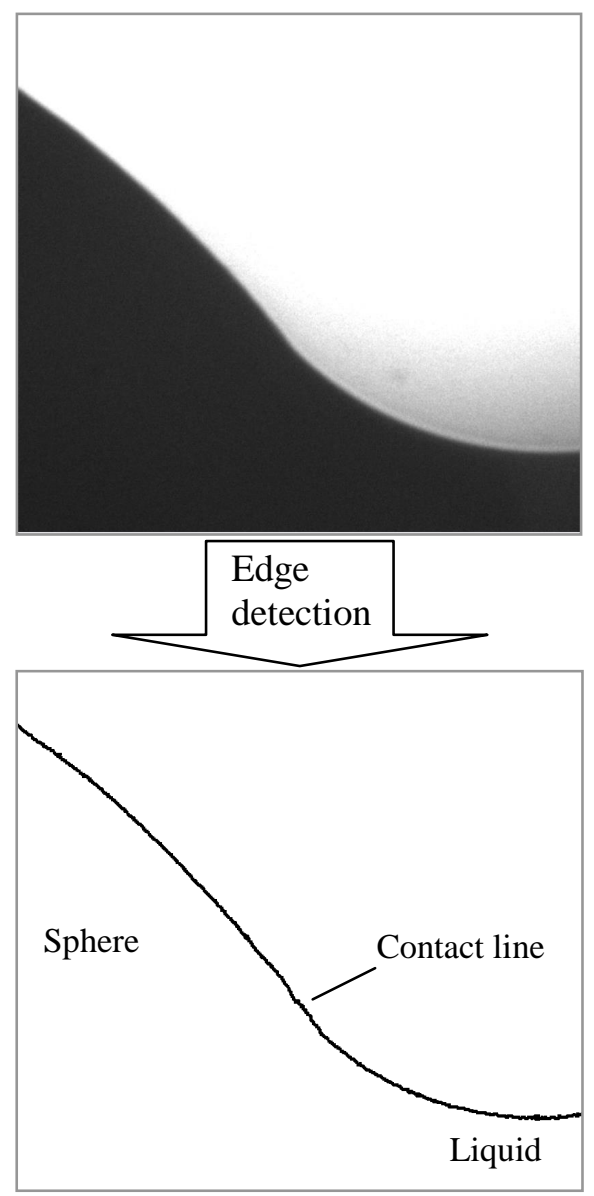

b)

Fig. 3 a) Schematic illustration of goniometer viewing plane, and b) raw image from goniometer (top) and after edge detection (bottom) for case 1. 


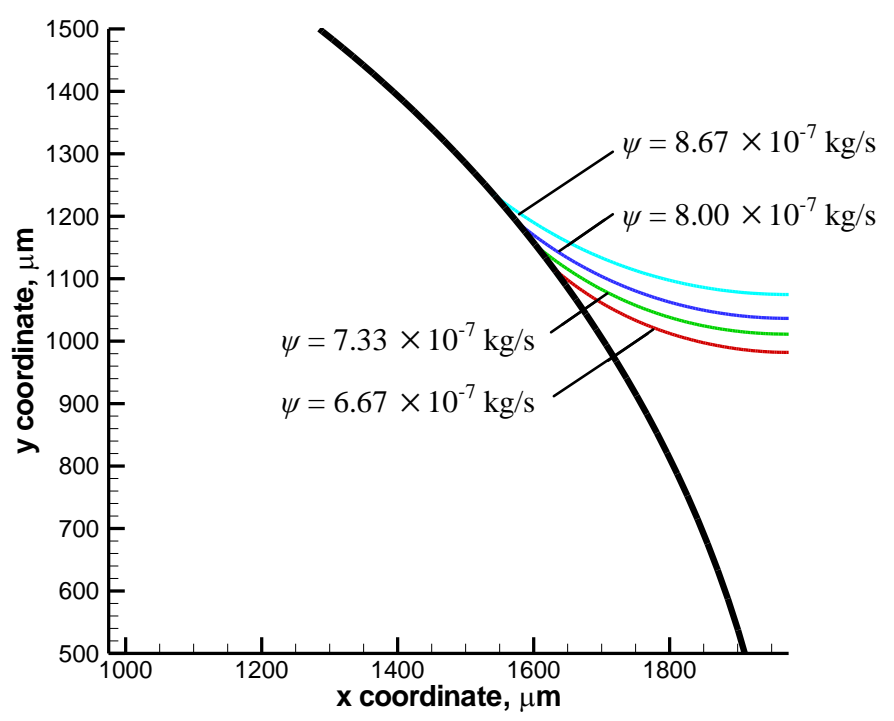

a)

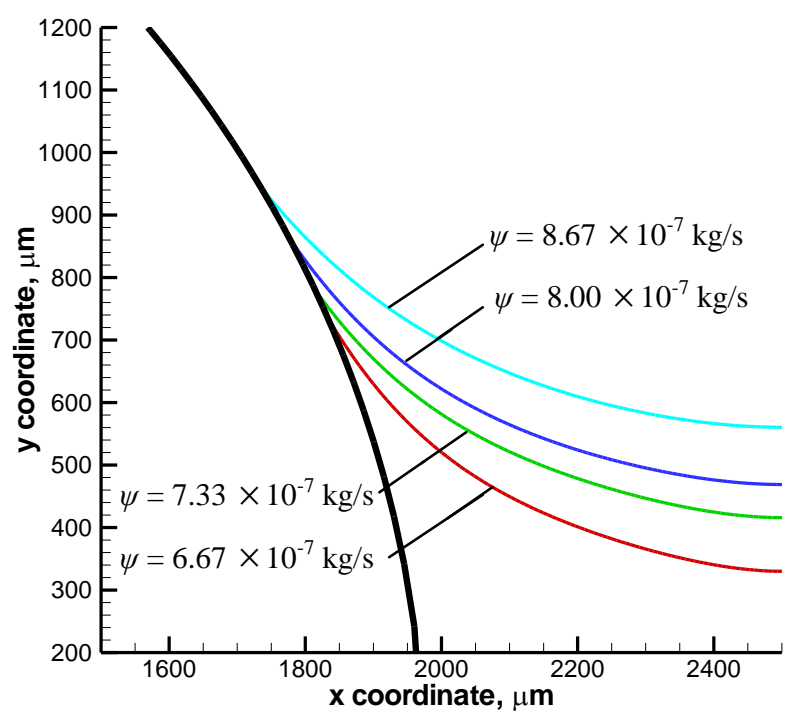

b)

Fig. 4 Meniscus profile dependence on liquid feeding rate $(\psi)$ for: a) cases $1-4\left(q_{n e t}^{\prime \prime}=3430 \mathrm{~W} / \mathrm{m}^{2}\right)$, and b) cases 7-10 $\left(q_{n e t}^{\prime \prime}=3420 \mathrm{~W} / \mathrm{m}^{2}\right)$. The dark line represents the sphere surface. The uncertainty in the experimental meniscus shape is up to $\pm 3.0 \mu \mathrm{m}$ at any point. 


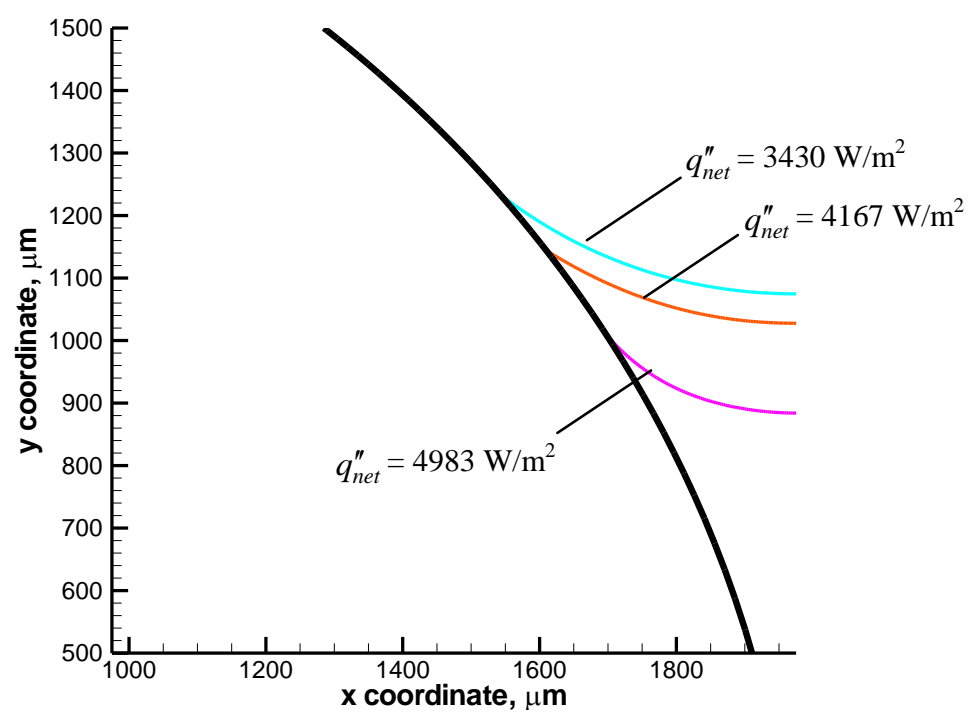

a)

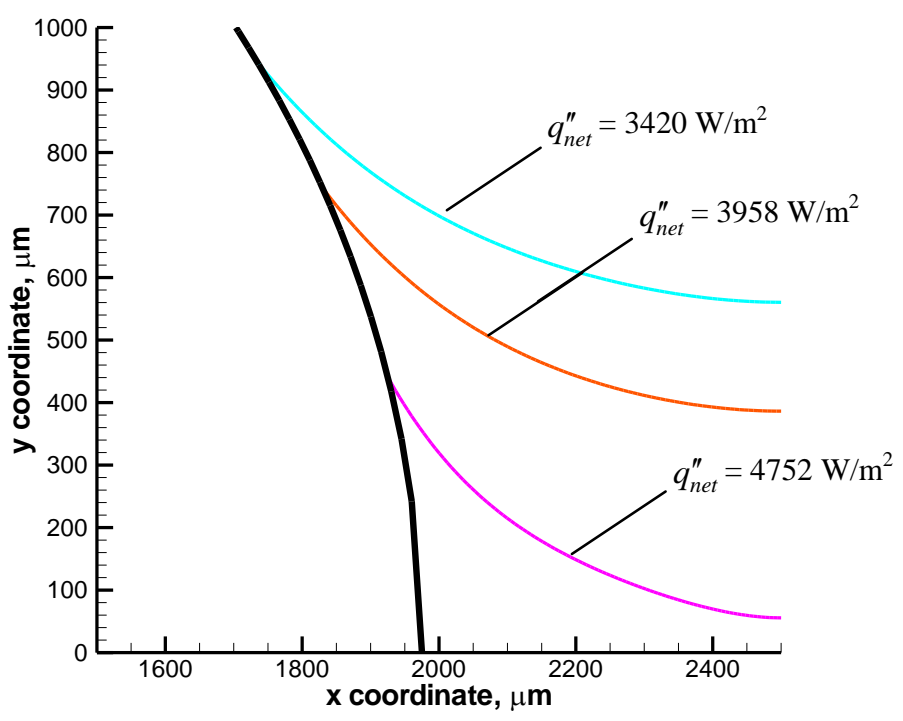

b)

Fig. 5 Meniscus profile dependence on net heat flux $\left(q_{n e t}^{\prime \prime}\right)$ for: a) cases 4-6 ( $\left.\psi=8.667 \times 10^{-7} \mathrm{~kg} / \mathrm{s}\right)$, and b) cases $10-12\left(\psi=8.667 \times 10^{-7} \mathrm{~kg} / \mathrm{s}\right)$. The uncertainty in the experimental meniscus shape is up to \pm 3.0 $\mu \mathrm{m}$ at any point. 


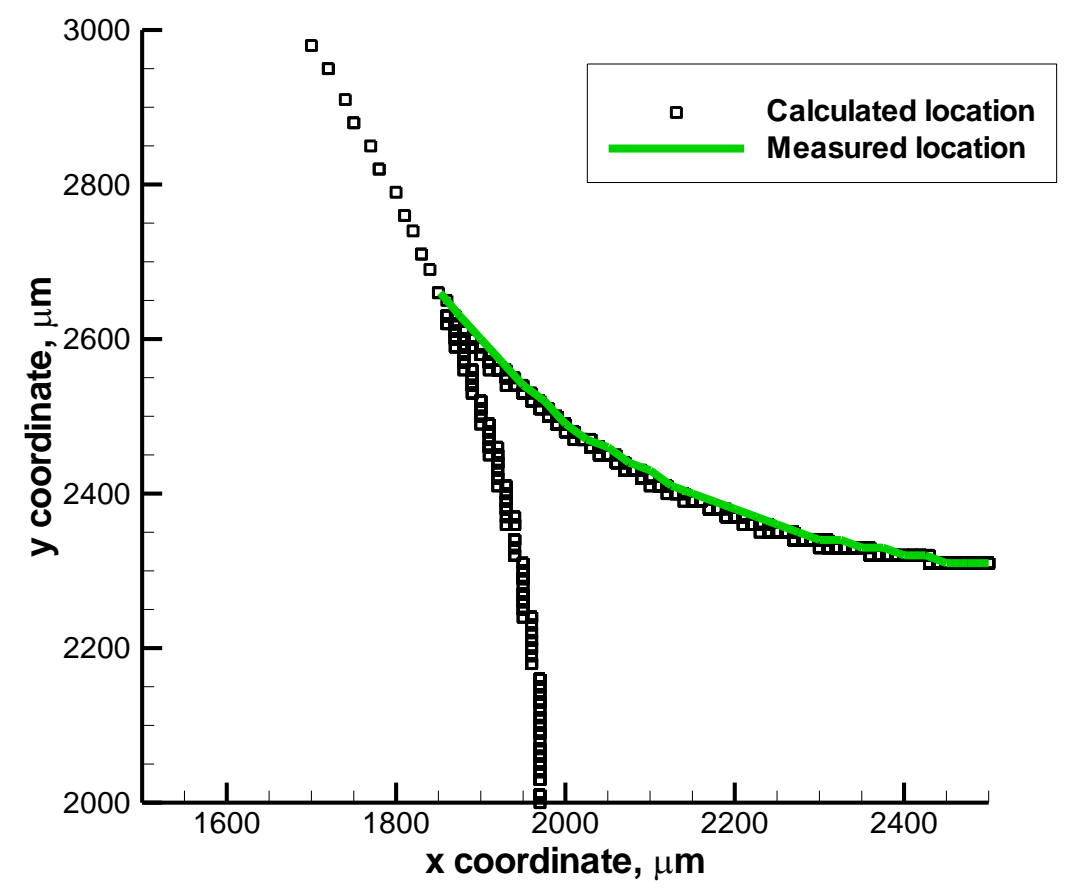

Fig. 6 Experimental meniscus profile (only selected points included for clarity) superimposed on calculated profile for case 7 . The uncertainty in the experimental meniscus shape is $\pm 1.8 \mu \mathrm{m}$ at any point. The calculated points represent vertices that are within $\pm 5 \mu \mathrm{m}$ of the experimentally imaged crosssectional plane. 


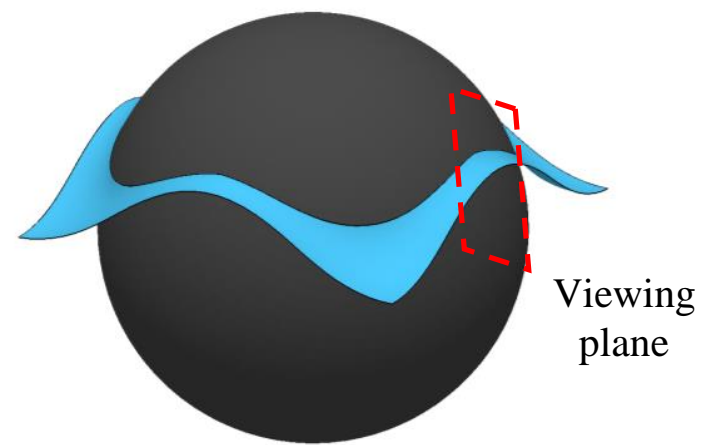

Case 6

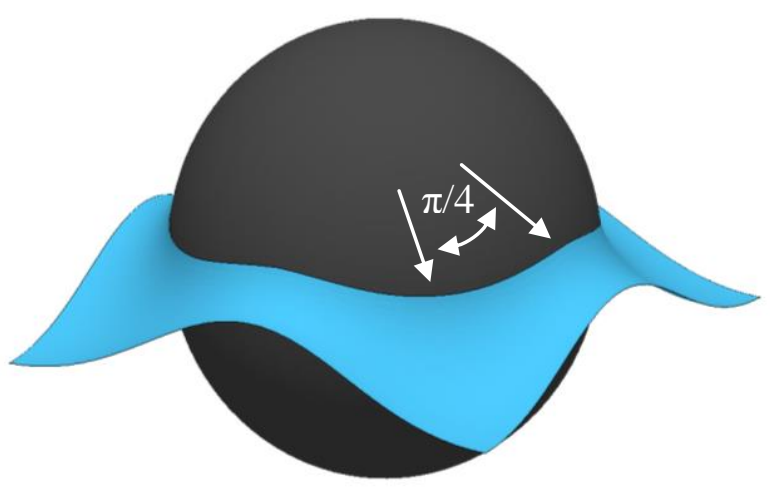

Case 12

Fig. 7 Calculated meniscus shapes for cases 6 and 12. While the menisci in all cases are nonaxisymmetric, cases 1-6 are more influenced by the presence of adjacent spheres as the meniscus rises higher in the viewing plane due to capillarity. In all cases, the microregion of $10 \mu \mathrm{m}$ thickness is shortest in the viewing plane and longest at a location shifted azimuthally by $\pi / 4$ radians (maximum difference $\sim 15 \%)$. 


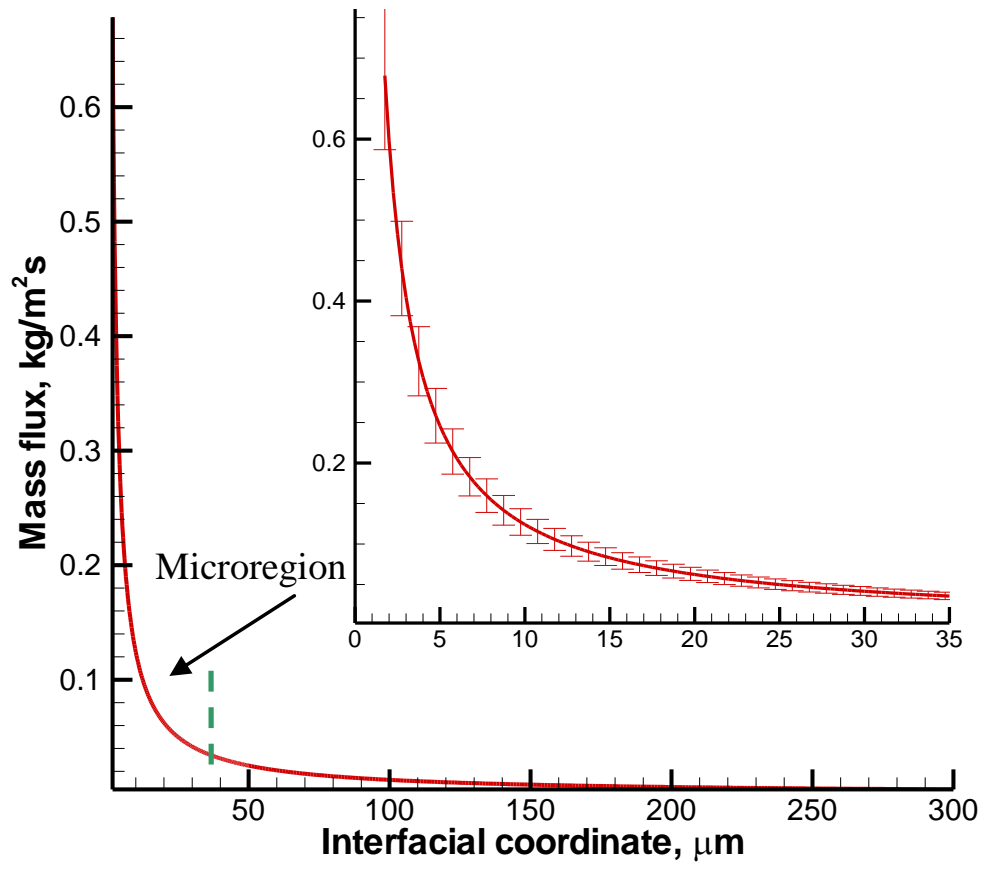

Fig. 8 Interfacial mass flux for case 7. Inset: interfacial mass flux in microregion with error bars. This figure is representative of other cases. 


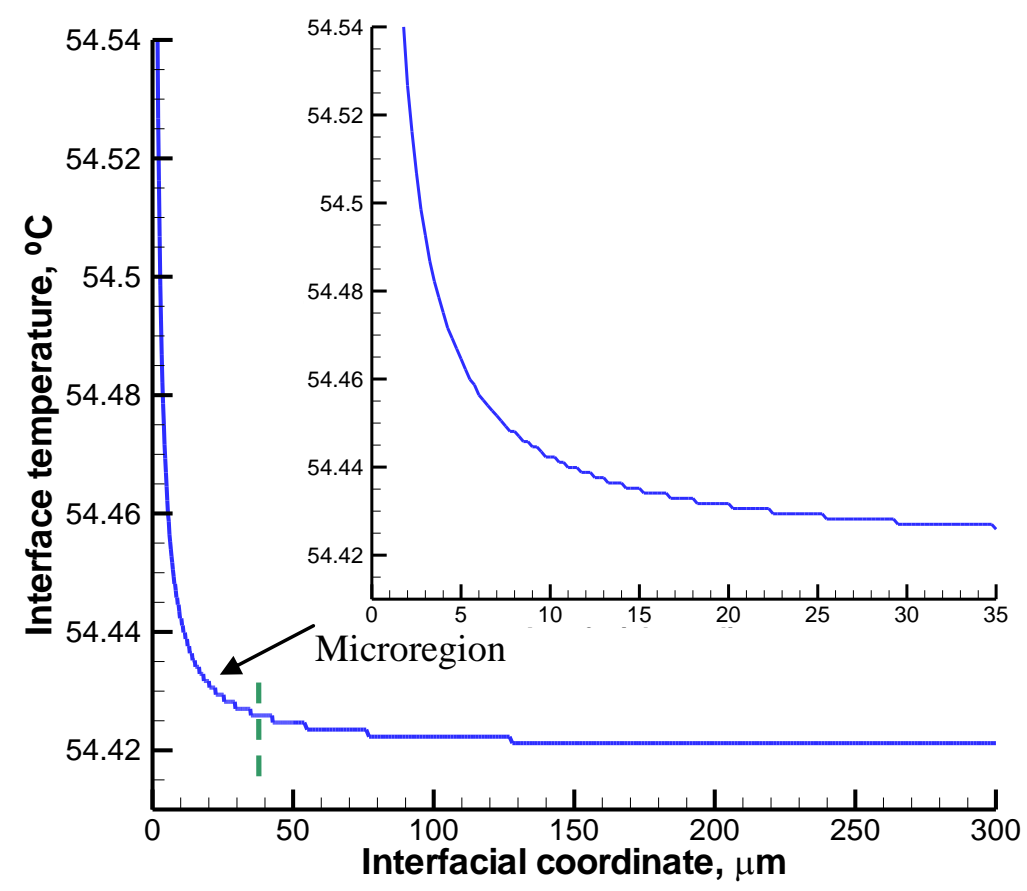

Fig. 9 Interfacial temperature for case 7. This figure is representative of other cases. 